\title{
Therapeutic Pearl: The Role of Sodium Hypochlorite in the Treatment of Chronic Hidradenitis Suppurativa
}

\author{
Muhammed Mukhtar (iD) ${ }^{1, *}$ \\ ${ }^{1}$ Mukhtar Skin Centre, Bihar, India \\ "Corresponding author: Mukhtar Skin Centre, Bihar, India. Email: drmmukhtar20@gmail.com
}

Received 2021 February 24; Revised 2021 April 20; Accepted 2021 April 24.

Keywords: Sodium Hypochlorite, Disinfectant, Cleaning, Germicidal, Hidradenitis Suppurativa

\section{Dear editor,}

Hidradenitis suppurativa (HS) is a chronic inflammatory disease of apocrine glands bearing areas, which presents with suppurativa nodules, sinuses, and scars in axillae and groins. The prevalence of HS is $0.05-4.1 \%$ (1). Numerous treatment strategies are available for HS, such as antibiotics, retinoids, anti-androgens, immunosuppressive, anti-inflammatory agents, adalimumab (anti-tumor necrosis factor antibody), radiotherapy, surgery, and laser, but none is very satisfactory $(2,3)$. Combination therapy with antibiotics and hyperbaric oxygen have shown promising results (3). Sodium hypochlorite is a very good disinfectant, which has been used in food factories and hospitals for waste products sanitization on a large scale for a long time. After the emergence of COVID-19, the solution of $\mathrm{NaOCl}$ is more commonly used in the sanitization of clinics and hospitals for the prevention of COVID19 infection. NaOCl works against a number of bacteria, yeasts, fungi, viruses except for spores and prions of the nose, mouth, and skin. On dilution of sodium hypochlorite, it releases nascent oxygen and chlorine, which decolonizes the above-mentioned micro-organisms. It acts by alterations in cellular metabolism, phospholipid destruction, irreversible enzymatic inactivation in microorganisms, and lipid and fatty acid degradation (4). Here, the author has used $\mathrm{NaOCl}$ solution in treating partially responsive stage II of HS along with antibiotics, retinoids, and zinc.

A moderately obese 18-year-old boy suffered from recurrent nodules, abscess and discharging sinuses, and scars in his both axilla for the last 1.5 years (Figure 1A). Biochemical laboratory findings were within normal range.
Initially, the patient was administered rifampicin (600 $\mathrm{mg} \mathrm{OD}$ ), isotretinoin (20 mg OD), and zinc ( $2 \mathrm{mg} / \mathrm{kg}$ body weight TID) for three months along with topical metronidazole and mupirocin. The abscess is drained out by the patient with the help of an aseptic disposable syringe barrel whenever it is required (Figure 1B). The patient was followed up fortnightly for six months. At the end of the 3rd month, number and size of lesions decreased, but discharging sinuses remained patent (Figure $1 \mathrm{C}$ and D). After three months of the medication, topical $\mathrm{NaOCl}(0.1 \%)$ was included in the combination treatment. $\mathrm{NaOCl}$ was applied topically thrice a day for 1 month. The sinus tracts healed within three to four weeks (Figure 1E and F). Nodules became non-tender. Thus, this case report concludes that there is a role of bacterial infection in the chronicity of $\mathrm{HS}$. NaOCl would be a good germicidal agent in treating hidradenitis suppurativa. In this combination therapy, dapsone(100 mg OD) could be added for fast resolution of inflammation and tenderness of the lesions. It is a preliminary report on the role of $\mathrm{NaOCl}$ in the treatment of $\mathrm{HS}$. For the role of $\mathrm{NaOCl}$ in $\mathrm{HS}$, it should be tried on a large number of Hidradenitis suppurativa patients with long-term follow-up.

\section{Footnotes}

Authors' Contribution: All works related to this article were done by the author.

Conflict of Interests: There is no conflict of interest. Funding/Support: There is no funding or financial support for this work. 

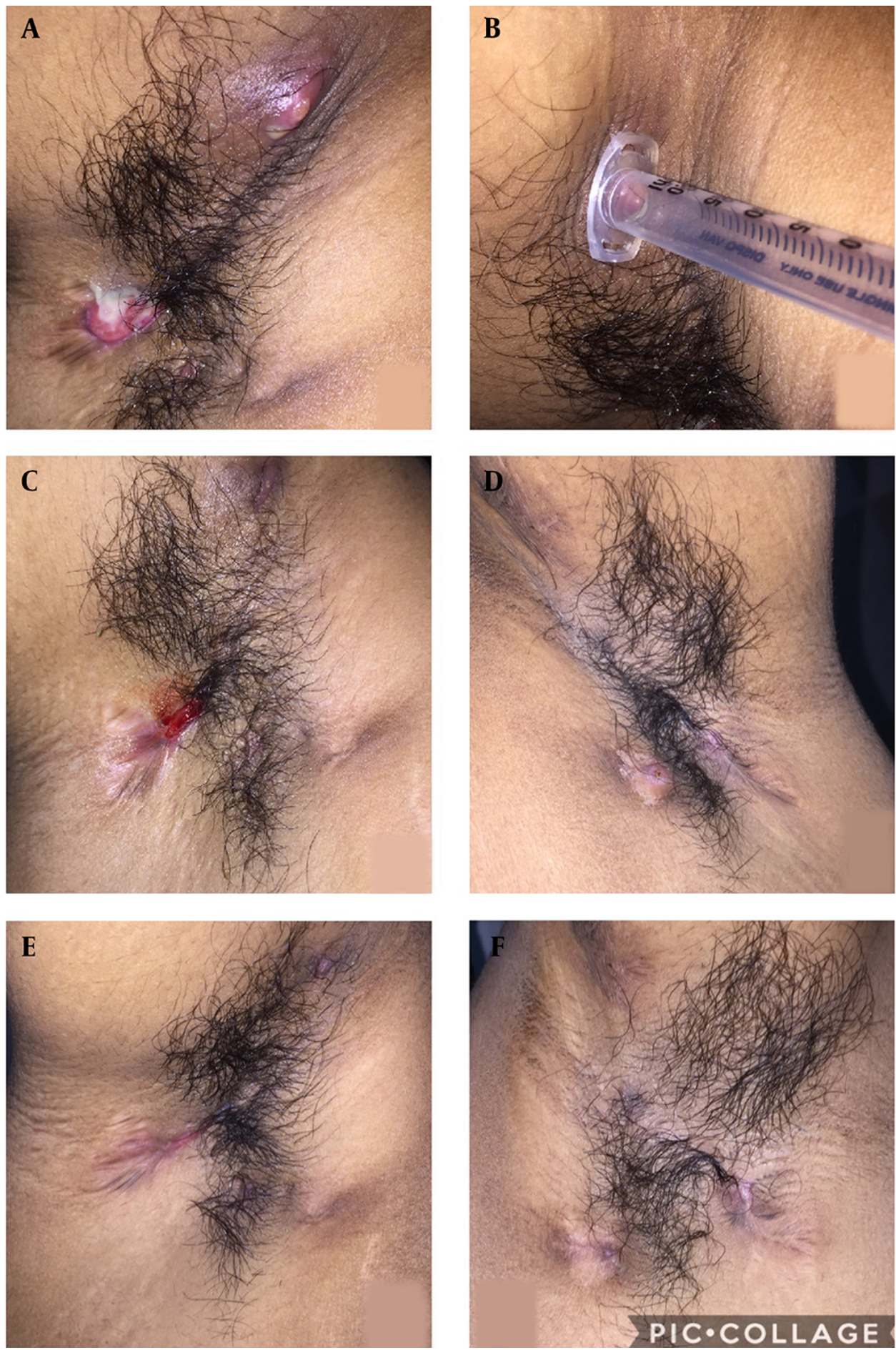

Figure 1. A, discharging nodules and sinuses of HS in axilla; B, the abscess of the HS lesions was being drained with the help of disposable syringe barrel; C and D, partially responsive HS after three months of the treatment; E and F, healed lesions of HS after topical application of NaOCl along with oral treatment at the end of 4 th month of follow-up. 


\section{References}

1. Saunte DML, Jemec GBE. Hidradenitis suppurativa: Advances in diagnosis and treatment. JAMA. 2017;318(20):2019-32. doi: 10.1001/jama.2017.16691. [PubMed: 29183082].

2. Tchero H, Herlin C, Bekara F, Fluieraru S, Teot L. Hidradenitis sup purativa: A systematic review and meta-analysis of therapeutic in- terventions. Indian J Dermatol Venereol Leprol. 2019;85(3):248-57. doi: 10.4103/ijdvl.IJDVL_69_18. [PubMed: 30924446].

3. Goldburg SR, Strober BE, Payette MJ. Hidradenitis suppurativa: Current and emerging treatments. J Am Acad Dermatol. 2020;82(5):106182. doi: 10.1016/j.jaad.2019.08.089. [PubMed: 31604100].

4. Fukuzaki S. Mechanisms of actions of sodium hypochlorite in cleaning and disinfection processes. Biocontrol Sci. 2006;11(4):147-57. doi: 10.4265/bio.11.147. [PubMed: 17190269]. 